\title{
Insights on Using WALC Platform as a Learning Tool
}

\author{
http://dx.doi.org/10.3991/ijep.v2i1.1891 \\ C.P. Leão, F. Soares and S. Costa \\ School of Engineering, University of Minho, Guimarães, Portugal
}

\begin{abstract}
WALC (Web Assisted Laboratory for Control engineering on-line education) platform was developed by a multidisciplinary team of university researchers. WALC is a configurable platform on Automation, Process Control and Numerical Methods subjects, enabling the on-line access to virtual and remote laboratories. Special emphasis was given to remotely access the platform, making WALC an educational tool. It is well known that students have different levels of motivation and different attitudes towards teaching and learning. Configurable learning environments play, then, a relevant role. Following this trend, using advances in technology, WALC is a platform in fast adaptation to new study methods. In order to understand the students' response, questionnaire results were analyzed and discussed.
\end{abstract}

Index Terms-Remote and Virtual Laboratories, Students perceptions, Web based learning.

\section{INTRODUCTION}

The new and innovative pedagogical approaches can effectively respond to students' needs and requirements, and, at the same time, promote their creativity [1]. As students have different levels of motivation, different attitudes towards teaching and learning methods, different responses to classroom environments and particular teaching practices, configurable learning environments must be considered. The new and innovative pedagogical approaches can respond effectively to students' needs. Being aware of these differences give teachers an opportunity to reach the diverse needs of their students [2]. Nevertheless, this implies a precise definition of objectives and skills to be acquired. Different learning tools available for a self-study help students to be successful in their college degree.

Following this trend, WALC platform (Web Assisted Laboratory for Control Engineering on-line Education) is being developed to facilitate the remote access, monitoring and control, to several laboratories, where students can complement their study by testing different case-studies (Fig. 1) [3, 4].

WALC is a Web environment applied to the Automation, Numerical Methods and Process Control teaching/learning in Engineering, where the theoretical and practical problems regarding each subject as well the relations they may have in common are available to the User. In Control teaching/learning process, for example, WALC allows the student to choose the practical engineering problem and the control type to be implemented. The user is also able to test different numerical methods to solve the referred problems. The available real-world problems include: DC Motor Control, Temperature Control of a Classroom, BakSim - Baker's Yeast fermentation, LabSim - Virtual Laboratory for control problems, Bar Control.

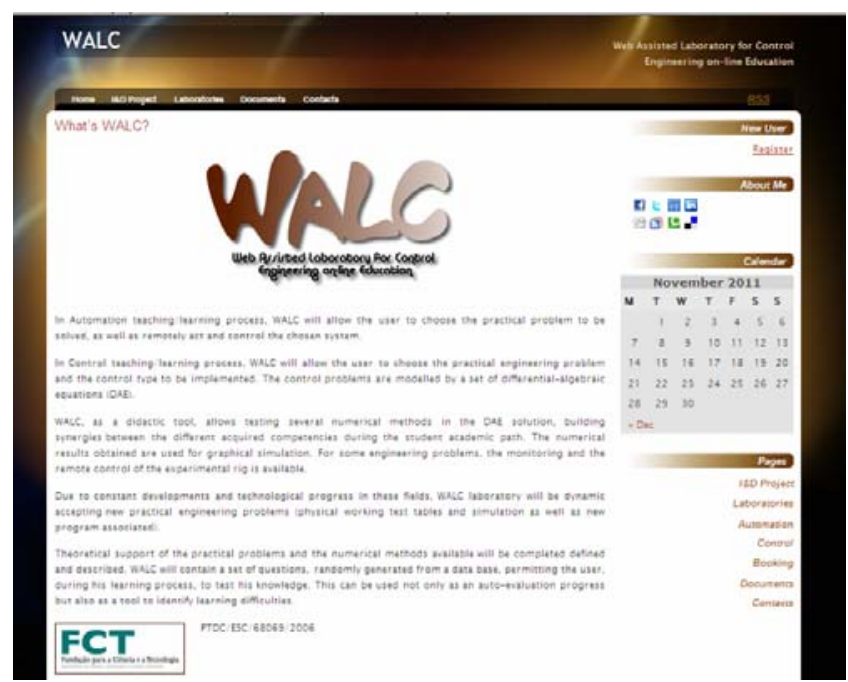

Figure 1. WALC Platform Interface for Control experiments (http://www.walc.netai.net/)

The access to the remote laboratories through WALC platform, testing different real-world control experiments, was proposed to students attending the Digital Control Curricular Unit (CU) taught in the $3^{\text {rd }}$ year, $2^{\text {nd }}$ semester, of the Integrated Master of Industrial Electronics and Computers Engineering. Students were invited to test the platform as an extra/optional work that was included in the formula to calculate the final grade of the CU.

Intending the WALC platform to be a feasible solution in teaching and learning process, it is necessary to perform reliable analysis of data obtained by surveys of students in the use of the platform itself; thus be able to infer the usefulness of this tool.

In order to understand how students react to this educational platform, a questionnaire was developed and given to students. Therefore, the questionnaire was designed to understand and analyze the students' reaction to the use of remote laboratories, by testing educational kits and accessing to theoretical contents, for teaching and learning. The questionnaire was then divided into six main parts: (1) characterization of the student, (2) identification of the work environment (operating system and identification of browsers), (3) educational kits: motivation (4), teaching kits: technical skills, (5) educational kits, and transverse (6), habits of students and characterization of the attitude during the project. To answer this questionnaire each student needed only about 5 to 10 minutes. Data were on-line collected by computer, through the platform and saved in a database for later analysis. 


\section{WALC PLATFORM - BRIEF DESCRIPTION}

WALC laboratory is a dynamic Web platform, developed in the University of Minho, accepting new practical engineering problems (physical working test tables and simulations). WALC is a complement learning paradigm centred in student interaction and experimentation, where users can produce, visualize and analyze, in real-time, results of practical experiences.

The aim is to develop, implement and introduce a web environment in a virtual and remote teaching/learning environment applied to Automation, Control and Numerical Methods in Engineering, providing the theoretical and practical problems in respect to each matter and the relationship between them.

In the teaching/learning Control subject, WALC platform allows students to choose the practical engineering problems and type of control to be implemented. The user is also able to test different numerical methods to solve these problems.

The real-world problems that are available include (Figure 2):

- DC Motor Control (speed control of an engine), Figure 3;

- Temperature control of a classroom, Figure 4;

- BakSim (the fermentation process), Figure 5;

- Bar Control (characterization of mechanical properties of a bar); Figure 6;

- LabSim (simulation of some control problems, for example hydraulic, thermal or electric), Figure 7.

The DC Motor Control is a remote accessed real-world experience, where the user can test a digital controller algorithm in motor velocity. The interface was developed in LabView from National Instruments. The experiment is controlled using a PID (Proportional, Integral and Derivative) algorithm in four different discrete versions. The remote user can test PID digital algorithms and parameters, change reference velocity values and register the motor output velocity profile [5]. The monitoring is performed by the graphical profile of motor velocity and error (difference in velocity reference and actual value) (Figure 3) and the visualization of the real motor through a webcam.

The kit temperature control of a classroom (Figure 4) allows the remote monitoring and on-off control of the temperature of a scale model classroom with reduced dimensions $(36 \mathrm{~cm}$ width, $34 \mathrm{~cm}$ length and $31 \mathrm{~cm}$ height) enabling high portability and autonomy. It is designed for a resistive temperature sensor with a positive temperature coefficient (PTC); controlled by a computer with custom software developed in LabVIEW using actuators for cooling and warming. It integrates a webcam to observe the activity inside the classroom, as well as the possibility to simulating a temperature disturbance. This scale model can be used to assist educational purposes stimulating students to real world problems.

BakSim, Baker's yeast virtual Simulation, is a virtual experience developed in LabView for virtual control and simulation of a bioreactor for baker's yeast fermentation, running in open or closed loop mode (Figure 5). It displays the most important system variables: biomass, ethanol, oxygen, glucose and dioxide of carbon. The BakSim application allows the study of the fermentation process,

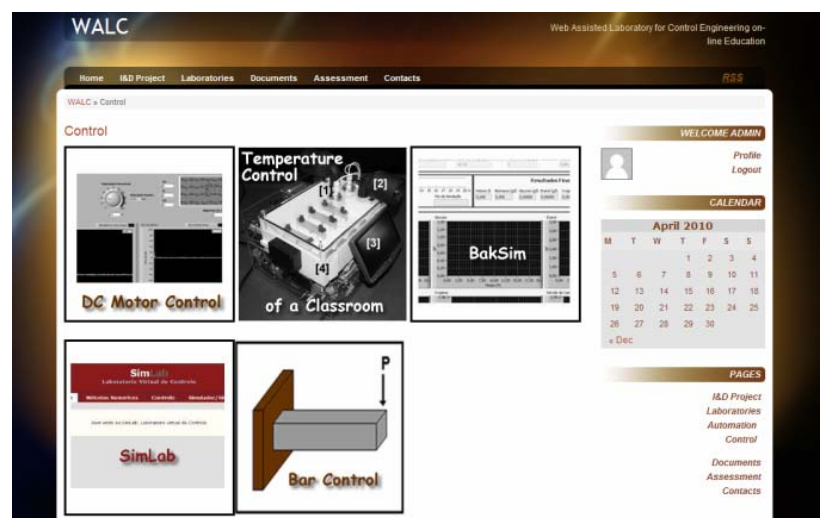

Figure 2. WALC Platform Interface for Control experiments.

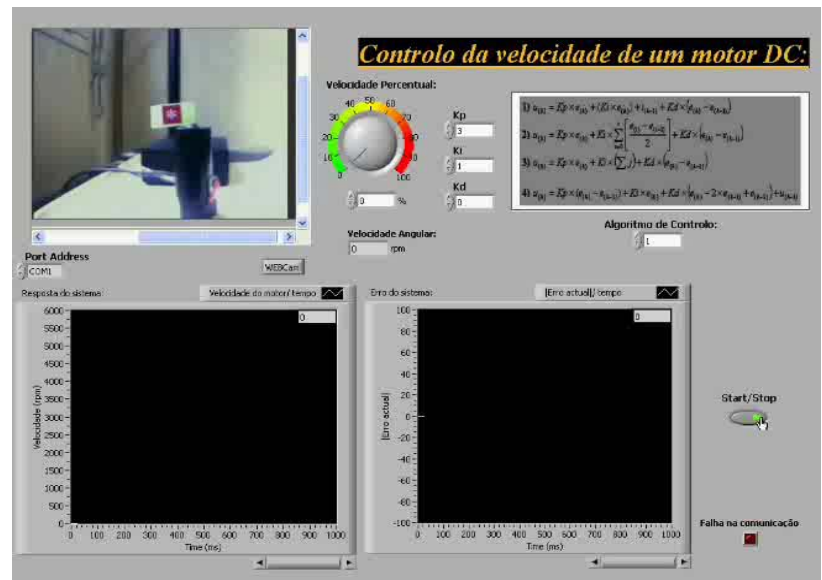

Figure 3. WALC Platform Interface for Control experiments: DC motor control.

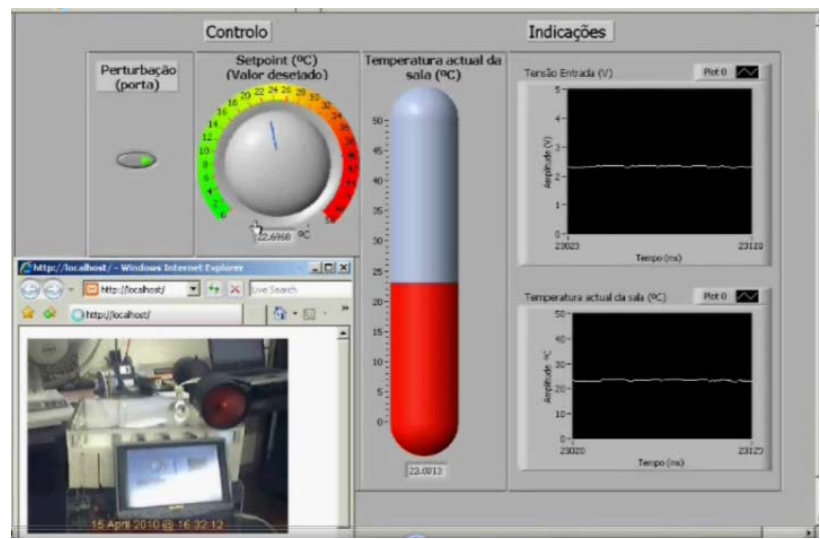

Figure 4. WALC Platform Interface for Control experiments: Temperature control.

the application of control laws, as well as the effectiveness of several numerical methods. It is worth mention the multidisciplinary aspect of this experience, as it puts together two areas of knowledge, Process Control and $\mathrm{Nu}-$ merical Methods [6].

Bar Control (Figure 6) is a virtual laboratory for the characterization of mechanical properties of a bar. The User can change the bar material, the applied force and its position in order to study the deformation and calculation of parameters.

SimLab (Figure 7) is a virtual laboratory for the simulation and modeling of real word problems in process con- 


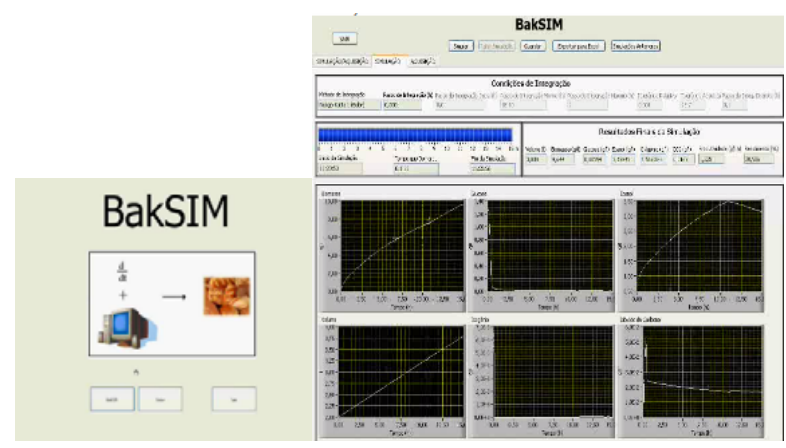

Figure 5. WALC Platform Interface for Control experiments: BakSim.

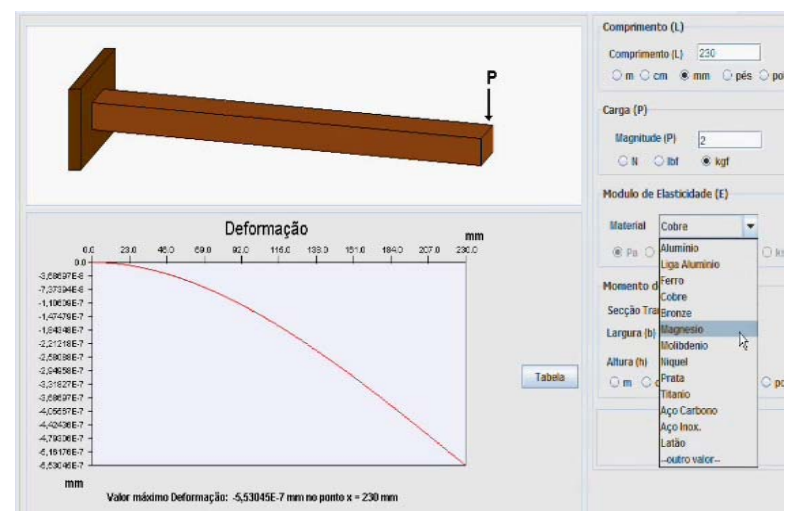

Figure 6. WALC Platform Interface for Control experiments: Bar Control.

trol engineering (hydraulic, electrical, mechanical andthermal systems are available for testing). One of the major goals of SimLab is to gather student's attention to how Numerical Methods can be straightly employed in Process Control real-world problems. Following this trend, different numerical methods are used in control simulations running in open and closed loop. In this case, on-off and PID controller can be employed. The User can change system and controller parameters. All the theoretical background is available in the webpage.

\section{WALC PLATFORM QUESTIONNAIRE EVALUATION}

The questionnaire developed was delivered to the $3^{\text {rd }}$ year students of Digital Control subject of the Integrated Master of Industrial Electronics and Computers Engineering. It was used to understand and analyze the students' reaction on the use of educational kits for teaching/learning process. The questionnaire was based on a previous one developed in earlier studies [7] and make available in the WALC platform (Figure 8).

Briefly, the questionnaire includes, after the student characterization, the work environment identification, the classification of the experiences performed motivation, technical skills, and soft skills, as well as the students' habits and attitudes characterization during the project.

The questionnaire was developed and make available on the platform in a predetermined week. The Surveys WordPress plugin [http://wordpress.org/extend/plugins/ surveys/] was used in its development. It allows creating questions with multiple choice or open answer. The survey plugin also facilitates to observe the survey result data in an aggregate or in an individual way. However, it only shows the numerical results of the answers given by students (for example, in terms of percentages) but does not

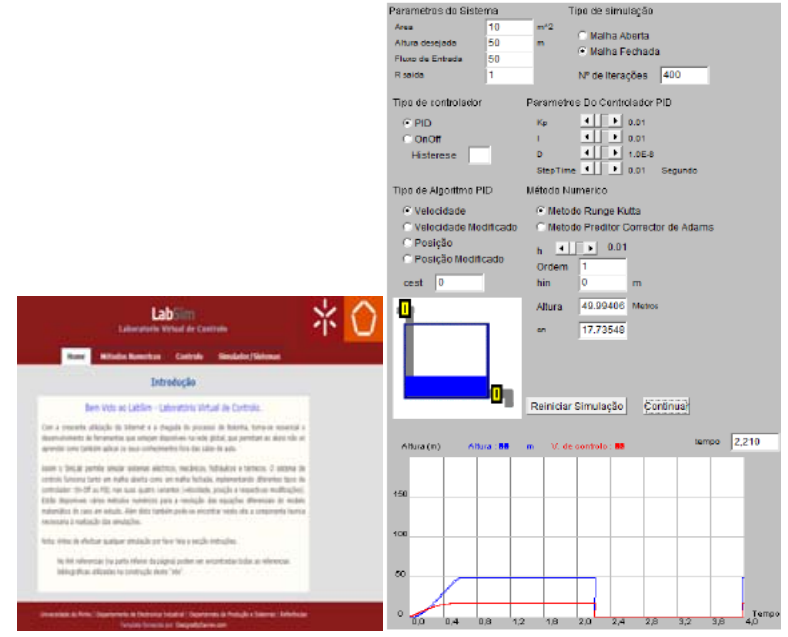

Figure 7. WALC Platform Interface for Control experiments: LabSim.

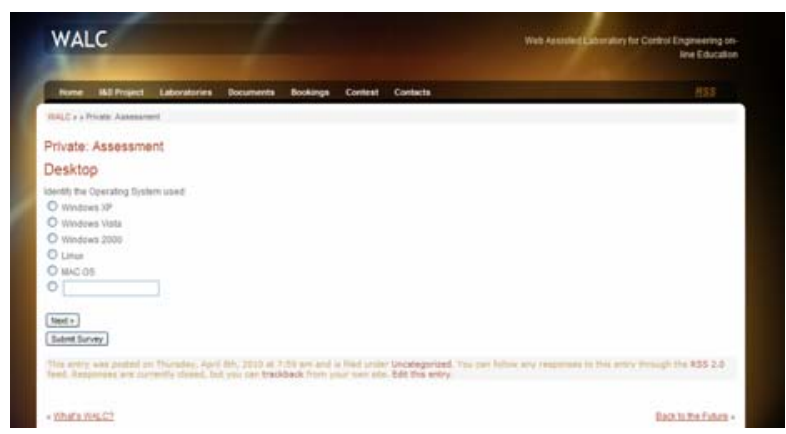

Figure 8. Part of the questionnaire used to evaluate students' perceptions on the WALC Platform.

study their relationships. So, it was necessary to use SPSS software [8], allowing testing a set of hypotheses, taking into account the number and nature of the sample, were defined and tested. In this way, this study goes further than the standard statistical analysis performed in previous study [7].

\section{A. Hypotheses defined}

The set of hypotheses defined and tested was as follows:

- Hypothesis 1: The use of the WALC platform is useful for student learning;

- Hypothesis 2: Carrying out the experiments ... 1) encourages collaborative work, 2) stimulates my intellectual curiosity, 3) provides knowledge to the student study area, 4) relates the subject of class with other subjects studied in other classes;

- Hypothesis 3: There are significant differences in students about the use of laboratories;

- Hypothesis 4: There is a relationship between time and the access site where the student accesses the platform.

\section{B. Student's characterization}

A group of 37 students from the Industrial Electronics and Computer Engineering course (IECE) responded to the challenge. Only three students were female (Figure 9), from ages between 20 and 25 years, with a higher frequency in 21 years. All the students attended the Digital Control subject ( $3^{\text {rd }}$ year) for the first time. 
PAPER

INSIGHTS ON USING WALC PLATFORM AS A LEARNING TOOL

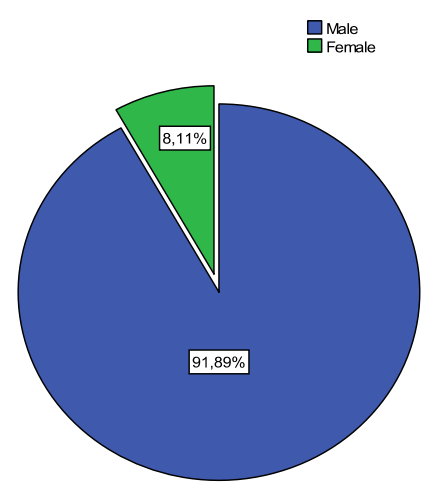

Figure 9. Sample Gender distribution.

\section{ANALYSIS RESULTS}

Considering the hypotheses stated in Section III, a statistical analysis was carried out in order to verify their authenticity.

1) H1: The use of the WALC platform is useful for student learning

Based on a 1 to 5 scale of agreement, where 1 indicates "Strongly Disagree" and 5 "Strongly Agree", the students' degree of concordance concerning their motivation in using the WALC platform as a useful tool on their Control and Automation learning process was analyzed.

$75 \%$ of the students indicated score higher than 3 , suggesting a positive reflection, and only three elements indicate level 1 ("Strongly Disagree"). No one selected level 2 ("disagree"). In average, the score obtained was 3.51 (near the "Agree" level).

It was possible to state that the majority of students $(70 \%)$ considered the WALC platform useful and very useful for their learning process, helping to assimilate the concepts learned throughout the semester $\left(\chi^{2}(3)=6.39, p\right.$ $>0.05)$.

2) H2: Carrying out the experiments ... 1) encourages collaborative work, 2) stimulates my intellectual curiosity, 3) provides knowledge to the student study area, 4) relates the subject of class with other subjects studied in other classes

The purpose of this hypothesis was to verify if the behaviour concerning the students' attitude facing four characteristics: encourages collaborative work, stimulates intellectual curiosity, provides knowledge to the students and allows the relationship of subjects studied in previous classes with the present, are analogous.

The scale of agreement used was the same as in the previous case ( 1 to 5 scale).

The results indicate that the differences between the students behaviour facing the different characteristics are not statistically significant in encouraging collaborative work, in stimulating the students' intellectual curiosity and in providing knowledge in the Digital Control area $(p>$ $0.05)$. However, not all the students agree on identifying and relating the subject in study with previous studied subject as Numerical Methods.

3) H3: There are significant differences in students about the use of laboratories

Several parameters relating to student motivation to learn the subjects taught, according to each laboratory, were evaluated. The average is above 3.88 for all labs ( 1 means "Strongly Disagree" and 5 "Strongly Agree"). This corresponds to an average rating of 4 next to a positive meaning that laboratories contributed and motivating students to learn the subject in study. Note that the minimum value chosen was 3, meaning "without opinion". The test was performed based on 8 respondents' students $(22 \%)$ correspondents to the students that had tested all the available laboratories.

No significant differences in the use of the available laboratories, as motivation for learning the material in study were obtained $(\mathrm{p}>0.05)$.

4) H4: There is a relationship between time and the access site where the student accesses the platform

This hypothesis tested the relationship between the time of the day that the students access the platform (09h-14h; 14h-22h-02h; or after 22h) and the access location (home, university, or other). In the morning there is a higher percentage of University access. This behaviour may be due to the fact that the class schedule of students in 3rd year is concentrated mainly in the morning. The afternoon period (14h-22h), the most active period with $82.4 \%$ students access to the platform from home and $50 \%$ access at the University (Figure 10).

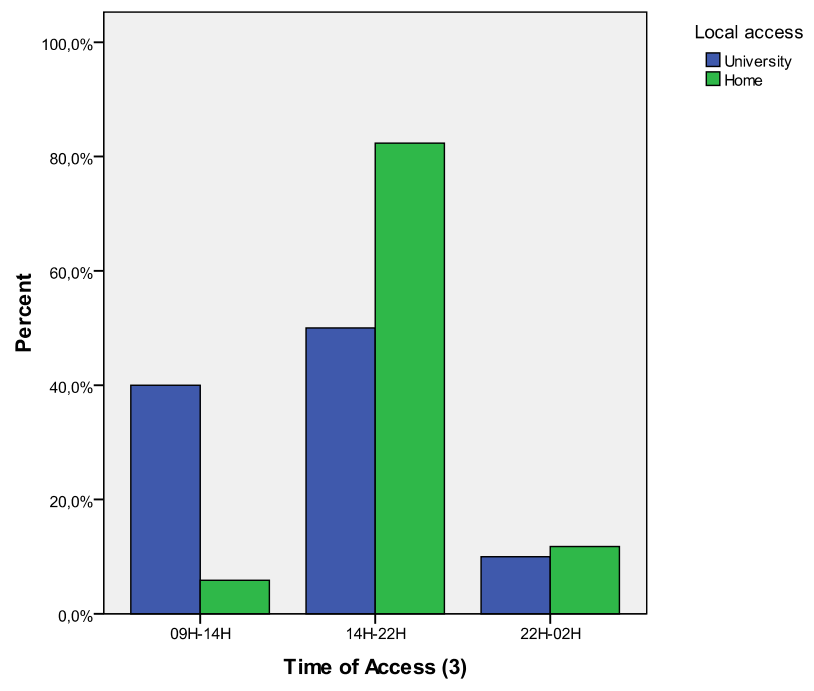

Figure 10. Period of time distribution by access location.

The results indicate that the differences between the students behaviour facing the time and location of platform access is statistically significant $(p<0.05)$, choosing the University as the place to access the platform and work in the available laboratories.

\section{FINAL COMMENTS}

The purpose of this article is to present the work carried out in WALC platform, analysing the survey fulfilled by the students in the Digital Control Course. For this work, it must be stressed also the importance of the survey design, being necessary to pay special attention to the data processing. It appears that it is essential to describe the sample so that the conclusions inferred from the hypotheses to be tested, have validity. Possibly, the data collection should have been more accurate, because on some days, some of the labs were not available, due to technical problems. On the other hand, it can thus be aware that the reso- 
PAPER

INSIGHTS ON USING WALC PLATFORM AS A LEARNING TOOL

lution of these technical problems has to be completed so that the same situation will not occur in the future.

The enthusiasm subsume by the students using the new tool, motivates the project expansion of being hailed as a future work to include more remote laboratories in the platform and on the recognition of the multidisciplinary of this area of study.

\section{ACKNOWLEDGMENT}

The authors are grateful to the students that participate in the study by using the WALC platform and fulfilling the questionnaires.

\section{REFERENCES}

[1] J. Gao, and J. Hargir, "Promoting Technology-assisted Active Learning", Computer Science Education.The Journal of Effective Teaching, Vol. 10, No. 2, 2010, 81-93.

[2] R.M. Felder and R. Brent, "Understanding students' differences", Journal of Engineering Education, 94, 2005, 57-72.

[3] S Costa, C P. Leão, F Soares, H Rodrigues, J Machado, "WALC Web Assisted Laboratory for Control Engineering On-Line Education", Controlo2010, 9th Portuguese Conference on Automatic Control, Coimbra, Portugal, 8 -10 September, 2010.

[4] S. Costa, F.O. Soares, C.P. Leão, "Mixing Personal Learning and Control Engineering Education Environments”, PAEE'2010 - Project Approaches in Engineering Education, Barcelona, Spain, 1-2 July 2010.

[5] V. Silva, V. Carvalho, R.M. Vasconcelos, and F.O. Soares, "Remote PID Control of a DC Motor", REV07, Porto, Portugal, 25-27 Junho, 2007, ISBN 978-3+89958-278-9.
[6] H.C. Oliveira, C.P. Leão, and F.O. Soares, "BakSIM - An application for control, monitoring and simulation of baker's yeast fermentation process", World Congress on Computer Science, Engineering and Technology Education Proceedings, New Engineering to a New World, 152-156, Edited by C.R. Brito and M.M. Ciampi, Itanhaém, Brazil, Março 2006. ISBN: 85-89120-30-9

[7] C.P.Leão, F.O.Soares, V.Carvalho, and R.M.Vasconcelos, "Automation and Control Engineering Laboratory: Students Perspectives", DOAJ, Lectures Notes in Engineering and Computer Science, Vol. 2185, Issue 1, 2010, 2017-2021. ISBN: 978-98818210-8-9.

[8] M.Norusis,SPSS 17. 0 Guide to Data Analysis, Prentice Hall, 2008. ISBN 0321621422.

\section{AUTHORS}

C. P. Leão, is with the Production System Department, School of Engineering, University of Minho, Guimarães, Portugal(e-mail: cpl@dps.uminho.pt).

F. Soares, is with the Industrial Electronics Department, School of Engineering, University of Minho, Guimarães, Portugal(e-mail: fsoares@dei.uminho.pt).

S. Costa, is with the Industrial Electronics Department, School of Engineering, University of Minho (e-mail: scosta@dei.uminho.pt).

This article is an extended version of a paper presented at the International Conference ICL2011, held in September 2011, in Piešt'any, Slovakia. This work was supported in part by the Portuguese Foundation for Science and Technology (FCT) through the R\&D project PTDC/ESC/68069/2006 and by the Algoritmi Research Center. Received 31 October 2011. Published as resubmitted by the authors 17 January 2012. 